\title{
Performance, Interaction, and Satisfaction of Graduate EAP Students in a Face-to-Face and an Online Class: A Comparative Analysis
}

\section{Dmitri Stanchevici E Megan Siczek}

Before arriving in a host country, international students may be motivated to complete some institutional requirements online. Many studies address computer-assisted instruction for second-language students, but few focus on fully online English for Academic Purposes (EAP) writing courses. This comparative case study, grounded in action research, examined the extent to which a fully online version of a graduate-level EAP course offered to international students at a North American university achieved comparable outcomes to a face-to-face version. A quantitative and qualitative analysis of study participants' performance and course evaluations indicated that the outcomes and student satisfaction of both cohorts were comparable. However, an examination of the participants' final research papers and online interactions revealed differences and challenges. Based on these findings, it is recommended that future online courses provide more instruction on source integration, library research, and building an interactive learning community. Overall, the findings suggest that when carefully designed, assessed, and refined, fully online courses hold strong promise in EAP academic writing contexts.

Les étudiantes et étudiants internationaux tiennent parfois à remplir certaines exigences institutionnelles en ligne avant de se rendre dans leur pays d'accueil. L'enseignement assisté par ordinateur pour les apprenantes et apprenants d'anglais langue seconde fait l'objet de nombreuses études, mais peu d'entre elles portent sur des cours d'écriture d'anglais académique (EAP) complètement dispensés en ligne. Entièrement basée sur la recherche-action, la présente étude de cas comparative fait état du degré de comparabilité des résultats d'un cours d'anglais académique de deuxième cycle complètement présenté en ligne à des étudiantes et étudiants internationaux inscrits à une université nord-américaine et des résultats obtenus lorsque le même cours était dispensé en personne. Une analyse quantitative et qualitative des rendements des participantes et participants et du cours lui-même a indiqué que les résultats et le degré de satisfaction des étudiantes et étudiants des deux cohortes se valaient. L'examen des rapports de recherche finaux des participantes et participants et celui des interactions en ligne ont toutefois révélé des écarts et des défis. Sur la base de ces constatations, il est recommandé que les futurs cours en ligne fournissent davantage d'instructions sur l'intégration des sources, sur les recherches en bibliothèque et sur la construction d'une communauté d'apprentissage interactif. Dans l'ensemble, les 
constatations de l'étude suggèrent que, s'ils sont soigneusement conçus, évalués et peaufinés, les cours complètement dispensés en ligne sont très prometteurs dans des contextes d'écriture en anglais académique.

KEYWORDS: online education, international students, English for Academic Purposes (EAP), second language writing, comparative analysis

\section{Introduction}

Online education in North America is steadily growing. J. E. Seaman et al. (2018) report that in 2016 more than $30 \%$ of all U.S. higher education students took distance courses, with more than three million students enrolled in distance courses exclusively and considerably more enrolled in distance and nondistance courses simultaneously. In Canada, more than 350,000 postsecondary students, approximately $18 \%$ of the total higher education enrollment, registered for at least one online course in 2016-2017 (Donovan et al., 2019). The growth in online education has coincided with the strategic internationalization of higher education and the continued high enrollment of international students in North American universities. In Canada, international students accounted for $12 \%$ of the total enrollment in public universities and colleges in 2016-2017 (Statistics Canada, 2018); in the United States, this number was 5.2\% for public and private universities in 2017-2018 (Institute of International Education, 2019). It is notable that much of this growth has been driven by Chinese students, who make up more than $33 \%$ of the international higher education enrollment in the United States (Institute of International Education, 2019) and almost $24 \%$ in Canada (Government of Canada, 2019). Given these increasing enrollments, universities have been motivated to innovate their curricula to better serve these students' learning needs. One promising mechanism for this is leveraging existing institutional support for the development and delivery of online courses for international students (Burgstahler \& Cory, 2008).

Although there is much literature on computer-assisted delivery in the context of language learning, few authors address second language (L2) academic writing courses. Moreover, these authors mostly focus on experimental studies, or web-enhanced or blended modalities; there is still a lack of research into L2 writing courses offered fully online and asynchronously (Vorobel \& Kim, 2012). It is of particular value to consider fully online writing instruction in English for Academic Purposes (EAP) settings, which involves the teaching of English in specialized academic contexts to develop students' capacity for further study in English (Hyland \& Hamp-Lyons, 2002). In addition to the development of academic literacy skills in English, EAP also promotes students' "familiarization with the target academic culture" (De Chazal, 2014, p. 6). Casanave and Li (2008) and Curry (2016) further 
emphasize the particular literacy practices associated with graduate study, when students need to develop awareness of the discourse conventions of their own disciplines. In recent years, there has been a growing scholarly focus on the needs and experiences of graduate student writers and the support mechanisms universities employ (Simpson et al., 2016), including the teaching of required academic writing courses in EAP contexts; however, there is a need for more scholarly work on the online delivery of such courses.

We respond to this gap with a comparative case study examining the extent to which a fully online version of a graduate-level EAP academic writing course achieved comparable outcomes with the face-to-face version. We first describe the broader institutional and program context in which both courses were offered, focusing on the rationale for offering the online course and on its design and development process. Second, we compare how well the study participants in both classes performed along three dimensions: in the EAP course in general; in their first year of graduate study at the university; and in their final research paper assignment for the course. Next, the online and face-to-face participants' contributions to electronic discussions are compared to evaluate the quality of student-student interaction. Finally, course evaluations in the online and face-to-face classes are described to compare students' perceptions of their EAP courses. We conclude by discussing the implications of our findings and by making recommendations for next steps. Based on our findings, it is clear that despite challenges, the creation of online EAP writing courses that leverage technology and maintain high standards for student learning presents considerable opportunities for institutions, EAP programs, and students.

\section{Literature Review}

Compared with face-to-face education, learning online has advantages and challenges. Online courses offer the convenience of a flexible schedule and the opportunity to avoid the high cost of living on or near campus. As a learning experience, online courses have such strengths as allowing students to work through the course materials and assignments at their own pace; offering abundant opportunities to practice written communication (Warnock, 2009); promoting social construction of knowledge and collaborative problem solving (Garrison, 2017); and developing students' reflective and critical thinking skills (Garrison, 2017). In addition to these benefits, international students taking an online course from their home country are able to engage with the authentic materials (Hsieh \& Liou, 2008) and the academic culture of the host country (Xing et al., 2008), without having to be physically present. The challenges of online education include slow uptake of educational technology by faculty members due to insufficient administrative, pedagogical, and technical support (Lawrence et al., 2014; Shebansky, 2018); higher dropout rates in fully online classes than those in blended or 
face-to-face classes (Harker \& Koutsantoni, 2005); students' lack of motivation because of unclear or delayed instructions and feedback (Karkar-Esperat, 2018); and students' perceived sense of isolation from their peers and instructor (Starr-Glass, 2014), which may be exacerbated by cultural differences in classes enrolling first language (L1) and L2 speakers (Karkar-Esperat, 2018; X. Liu et al., 2010; Yim, 2011).

Despite these challenges, the outcomes of online learning have been found to be comparable with or even better than those in face-to-face education. Allen and J. Seaman (2016) reported that in 2015 more than 70\% of "academic leaders rate[d] the learning outcomes in online education as the same or superior to those in face-to-face instruction" (p. 5). Similarly, in a meta-analysis of 37 studies on second and foreign language pedagogy over a more than 30-year period, Grgurovic et al. (2013) found a general agreement that computer-assisted instruction produced better results than instruction without computer technology. In a study focusing on ESL programs in Ontario, Lawrence et al. (2014) found that "many administrators, instructors and learners recognized the complementary value of face-to-face learning with online learning" (p. 13).

The outcomes in computer-assisted L2 academic writing courses have likewise been found to be positive in research studies. However, few of these studies have dealt with fully online courses; instead, most of them focused on online components as a supplement to a regular face-to-face course. For example, internet-based resources have been found useful in EAP classes for providing dynamic feedback in various formats (Séror, 2012; Slavkov, 2015); teaching authentic tasks, such as email writing (Jarvis, 2001); developing EAP students' web-literacy, including the ability to evaluate the origin and credibility of web-based sources (Stapleton, 2003); and combining various online materials (readings, videos, and exercises) to develop students' rhetorical "meaning making process" in academic writing (Zhang, 2018). Hsieh and Liou (2008) reported the positive outcomes of using an online component in a face-to-face class for teaching abstract writing based on corpus analysis. Xing et al. (2008) conducted a study in which an experimental group of Chinese students in a U.K.-based academic writing course participated in a supplemental e-course for 20 min every other week in addition to the regular face-to-face meetings. As a result of being exposed to materials targeting the rhetorical features of an academic text and an opportunity to interact with L1 participants in the course, these students did better than their counterparts in the control group who had not participated in the e-course.

These studies confirm the value of online learning in an L2 EAP writing class. However, they reflect a relatively limited use of computer and internet technology, such as authentic materials or enhanced interactivity, rather than fully online pedagogies (Colpaert, 2006). In this regard, Harker and Koutsantoni's (2005) study is interesting because it compared the outcomes of an EAP course delivered in two modes, blended and fully online. It was found that 
while the students' performance and satisfaction were comparable in both modes, the retention was much better in the blended version. Harker and Koutsantoni speculated that the fully online students' time commitment to the course had initially been lower than that of the students in the blended course. Significantly, student-student discussions were "encouraged," not required, in both modes (p. 201). Thus, the higher level of interaction in the blended course occurred simply because they had to physically meet, and the resulting sense of community may also have ensured a higher retention (p. 210). This study is informative for designers of online L2 academic courses, but its limitation is that it focused on a nondegree voluntary course. The outcomes, including the retention rate, could have been different in an online course that students were required to complete. The present study contributes to the literature on L2 online learning by focusing on a required graduate-level EAP writing course enrolling international students before they arrive in a host country for their degree program. This course was offered fully online and asynchronously.

\section{Context and Research Questions}

This study is situated within the context of the EAP program of a researchintensive private university in the U.S. mid-Atlantic region; this program, housed in the university's arts and sciences college, primarily teaches required academic writing courses to L2 international students who have matriculated in degree programs. Its goal is to develop students' academic literacy skills so they can better meet expectations for written communication in their new academic discourse community. The EAP program's instructional practices are grounded in the fields of Teaching English to Speakers of Other Languages (TESOL), applied linguistics, and writing studies, and its pedagogy draws on academically purposed content and materials using a task-based approach. The requirement to take EAP is based on longestablished university policy: International students who are admitted to the university with Test of English as a Foreign Language (TOEFL; or equivalent) scores below 100 are required to successfully complete an EAP academic writing and research course during their first semester of study. EAP offers two graduate-level courses, both of which take a scaffolded pedagogical approach to developing L2 international students' readiness for the academic literacy tasks they encounter in their graduate studies. The lower level course targets foundational skills while the upper level course addresses more advanced academic literacy skills for higher proficiency students.

In line with the university's strategic plan to increase international student enrollments at the graduate level from $25 \%$ to $30 \%$ of the student population by 2021, the program has experienced significant growth in recent years. For example, in 2011-2012, the EAP program enrolled 241 graduate students, and by 2016-2017, enrollments reached nearly 600 students. This upsurge resulted 
in a high demand for EAP classes, which in turn contributed to increased visibility and institutional legitimacy for the program. The program also enjoys considerable autonomy in curricular innovations. However, the rapid growth of the program has created challenges, including a heavy dependence on part-time faculty; an uneven distribution of classes because most students take their required EAP class in the fall semester and very few in spring and summer; scheduling difficulties; and a lack of investment in building program capacity caused by a university budget model that generates revenue for students' enrolling college rather than the one that provides the instruction. Although we had moderate success promoting summer on-campus EAP classes, which enabled admitted students to acclimate to campus while developing their academic writing skills with a "live" community of peers, it was extremely costly for students to pay both tuition and living expenses for the additional time on campus.

These opportunities and constraints motivated a new curricular approach to delivering the required EAP academic writing course to admitted graduate students. On a program level, we saw the development of online EAP sections as a means to streamline course content in support of learning objectives. Such streamlining would promote consistency across sections, as well as allow faculty to concentrate on providing high-quality feedback and interacting with students rather than developing instructional content. Offering EAP online was also motivated by an institutional commitment to the development of online classes, including instructional design and technical support, as well as a more favourable budget model. Finally, we assumed that prospective EAP students would see the value of a summer online class because they could fulfill their EAP requirement from their home country prior to arrival on campus, avoid additional expenses related to on-campus summer study, and start their graduate programs in fall semester equipped with foundational academic writing skills.

Our first attempt at converting an EAP course to an online format involved the lower level graduate academic research and writing course required for students who were admitted to the university with a combined score of 41 or below on the writing and speaking sections of the TOEFL. A face-to-face graduate EAP course, three sections of which were offered in spring 2018, served as the basis for a pilot online course taught in summer 2018 by the same instructor. In both versions, students were expected to develop a rhetorical awareness of typical academic genres; acquire library research skills; learn to critically read, integrate, and cite academic sources in their writing; learn to provide peer feedback and revise in response to peer and instructor feedback; improve their academic grammar and vocabulary; and develop oral presentation skills. In addition to short written assignments, the students' main productive output was a source-based argumentative research paper that engaged all of the above learning objectives. Although the two course versions differed in length, the face-to-face course being 
offered in a 14-week spring semester and the online course in a 6-week summer semester, students were expected to spend the same amount of time on the course: $112.5 \mathrm{hr}$ per semester.

The face-to-face version included a fairly extensive asynchronous online component. In addition to regular classroom meetings, every week, students had to contribute to the discussion board on Blackboard (the university's learning management system) with responses to the instructor's prompts, replies to classmates' responses, and critiques of classmates' drafts. These students also used VoiceThread, an online slide presentation tool, to introduce themselves and create a draft of their oral presentation assignment. Adding an online component to a face-to-face class gave students opportunities to practice written communication and oral presentation skills at their own pace, as well as ensuring that every student engaged in class discussions consistently and meaningfully.

These asynchronous learning activities, along with the face-to-face course's learning objectives, content, and assignments, were transferred into the online version of the course. It was developed by the instructor in collaboration with a university instructional designer, who offered systematic guidance on technical and instructional aspects of the online course. To ensure comportment with best practices for online instruction, the course passed a Quality Matters review and was approved for teaching in summer 2018. A total of 15 students enrolled and successfully completed the course. They read assigned materials; watched instructional videos; completed written assignments with drafts, peer critiques, and revisions; and participated in whole-class or small-group discussions using either written posts on the discussion board or oral slide presentations on VoiceThread.

To compensate for a lack of regular student-instructor contact in classroom meetings, the instructor used videos to introduce himself and to provide instruction. Also, compared with the face-to-face version, the instructor posted more written announcements and made more comments on the online discussions. To promote a high quality of student-student asynchronous interaction, the discussion board and peer critique assignments were introduced with clear instructions about the due dates; word counts; and the number, content, and organization of the posts. The instructor provided examples of what was expected in writing and in video presentations. A clear rubric explained how each contribution would be graded. In short, the decisions made during the online course design process reflected EAP's overall pedagogical approach and set high standards for transparency and engagement that offset the limitations of a class with no classroom-based contact.

Although the administrative and pedagogical rationales for developing an online version of a graduate EAP class were clear, it was important for us to engage not only in reflection but also in a deeper analysis of the extent to which online students had an experience and outcomes that approximated 
those of face-to-face students. Consequently, this comparative case study addresses the following three research questions:

Research Question 1 (RQ1): To what extent are the outcomes in the face-to-face and online classes comparable?

Research Question 2 (RQ2): To what extent are the quantity and quality of student-student interactions comparable in the face-toface and online classes?

Research Question 3 (RQ3): How did students evaluate their experience in the face-to-face compared with the online course?

\section{Method}

Because we wanted to understand whether an online version of the course resulted in similar engagement and outcomes for students, we employed a comparative case study methodology. According to Yin (2017), comparative research approaches are more compelling than investigations of a single case and enable researchers to draw stronger analytic conclusions, especially in the case of researching instructional interventions. This study also represents a form of action research. A defining feature of action research is that the researchers are themselves practitioners, who are both reflective of their own pedagogy and invested in guiding instructional and curricular development at a program level (McNiff, 2013).

Of the 45 students from the face-to-face sections, we selected 15 who were as comparable as possible with the 15 students in the online version based on the TOEFL (or equivalent) score that placed them into this particular EAP level, their country of origin, and their field of study. All 30 study participants were from China, which reflects the program's overall enrollment pattern. The participants' majors can be found in Table 1 below.

Table 1

Majors in the Face-to-Face and Online Cohorts

\begin{tabular}{|c|c|c|c|}
\hline \multicolumn{2}{|c|}{ Spring 2018 (Face-to-Face) Cohort } & \multicolumn{2}{|c|}{ Summer 2018 (Online) Cohort } \\
\hline Field of Study & Count & Field of Study & Count \\
\hline Bioinform/Molecular Biochem & 1 & Sociology & 1 \\
\hline Statistics & 1 & Statistics & 1 \\
\hline Rehab Counselling & 1 & Museum Education & 1 \\
\hline Finance & 1 & Information Systems & 1 \\
\hline Computer Science & 3 & Computer Science & 8 \\
\hline
\end{tabular}




\begin{tabular}{lclcc}
\multicolumn{2}{c}{ Spring 2018 (Face-to-Face) Cohort } & \multicolumn{3}{c}{ Summer 2018 (Online) Cohort } \\
\hline \multicolumn{1}{c}{ Field of Study } & Count & \multicolumn{1}{c}{ Field of Study } & Count \\
\hline Computer Engineering & 1 & Electrical Engineering & 2 \\
Electrical Engineering & 5 & Mech/Aerospace Engineering & 1 \\
Mech/Aerospace Engineering & 2 & & 15 \\
\hline Total & 15 & Total & \\
\hline
\end{tabular}

To compare their experience in the face-to-face and online version of the class more deeply, we adopted a mixed methods approach to data collection and analysis (Yin, 2017). The four main data sources and analytical approaches are outlined below:

- Participants' EAP grades and first-year grade point average (GPA) were analyzed statistically.

- Participants' final research paper grading rubrics with scores were analyzed statistically. The instructor's written comments were also analyzed for salient feedback problems.

- Participants' replies to classmates' posts on the discussion board and participants' peer critiques (57 posts in each cohort) were used to evaluate the quantity, in terms of word counts, and the quality of student-student interaction. Based on Hewings et al.'s (2009) study, we subjected the discussion replies and peer critiques to a discourse analysis to identify and count rhetorical moves that build social relationships: Encouragement, Deferring, Salutation, and Signing Off. In addition to these moves, we counted posts that used Criticism, as well as a Direct Address (addressing the classmate with you and your) and Indirect Address (referring to the classmate in the third person with he or she, or by the classmate's name, or with phrases such as "the author" or "this draft"). Also following Hewings et al. (2009), we verified the significance of the findings from our discourse analysis by subjecting the discussion replies and peer critiques to a corpus analysis. Using the Concordance function of AntConc 3.5.8 (Anthony, 2019), we counted the occurrences of the pronouns you, your, we, us, our, he, him, his, she, and her. The frequencies of such pronouns in student-student interactions are indicative of social relationships in a class.

- University-administered course evaluations in both versions and an additional survey in the online version were compared statistically. Students' written comments to open-ended question prompts were also analyzed for salient themes. Unlike the above analyses, which used the materials of the 15 students in the online class and the 15 students sampled from the face-to-face sections of the course, the course evaluations came from all students in the spring and summer semester who participated in the 
evaluations (33 in the face-to-face sections and 15 in the online section). In addition, five students from the online class participated in a separate instructor-created course evaluation survey.

\section{Results}

The analysis of data described in the previous section yielded four main findings, which are summarized below and further analyzed in the discussion section that follows.

\section{Analysis of Participants' Final EAP Course Grades and First-Year GPA}

As noted above, the study participants matriculated in a diverse array of graduate programs, though the predominant fields of study were computer science and electrical engineering (see Table 1). Because of this disciplinary diversity, the goal of the EAP class is to build students' genre and rhetorical awareness and develop their foundational academic literacy skills, rather than prepare them for the specific content expectations of their programs of study. We wanted to ensure that students who enrolled in the online summer version of the course performed similarly to their face-to-face peers and did not appear to be disadvantaged in their graduate coursework. In an analysis of the participants' academic performance, we found that those in the online cohort had slightly lower average grades in the EAP class (3.6/4 compared with 3.8/4) but performed somewhat better in their first semester of study in their programs (3.62/4 compared with 3.49/4). By the end of their first full academic year, the GPA for the participants in the online section compared with the face-to-face section were 3.58/4 and 3.54/4, respectively. In short, we found a high level of comparability when examining the participants' final grades in the EAP class and their performance in their first year of study in their respective graduate programs.

\section{Analysis of Participants' Performance on the Final Research Paper}

To develop a more granular understanding of the extent to which participants met course learning objectives, we examined the main productive output of the course, a source-based argumentative paper that comprised $30 \%$ of the final grade and engaged all learning objectives of the EAP course. We believe that students' performance on this assignment is an important measure of their performance in the EAP course in general. In both the face-to-face and the online version of the class, the approach to and the grading rubric for the research paper were the same. The final research paper was preceded by two peer- and instructor-reviewed preliminary drafts and an oral presentation (in class for the face-to-face students and on VoiceThread for the online students). The grading rubric for the final research paper included four 
areas with a 25-point maximum score for each (100 points total): General Approach, Content and Organization, Use of Sources, and Format and Editing. Table 2 lists the means and standard deviations of the scores for each of the four categories and of the total scores received by the 15 participants sampled from the face-to-face course and the 15 participants from the online course.

Table 2

Summary of Means and Standard Deviations for Final Research Paper Scores in the Face-to-Face (FtF) $(n=15)$ and Online $(n=15)$ Cohorts

\begin{tabular}{|c|c|c|c|c|c|c|c|c|c|c|}
\hline \multirow[t]{2}{*}{ Rubric } & \multicolumn{2}{|c|}{$\begin{array}{c}\text { General Approach } \\
\text { (25 max) }\end{array}$} & \multicolumn{2}{|c|}{$\begin{array}{c}\text { Content and } \\
\text { Organization } \\
(25 \text { max })\end{array}$} & \multicolumn{2}{|c|}{$\begin{array}{l}\text { Use of Sources } \\
\text { (25 max) }\end{array}$} & \multicolumn{2}{|c|}{$\begin{array}{c}\text { Format and } \\
\text { Editing } \\
\text { (25 max })\end{array}$} & \multicolumn{2}{|c|}{$\begin{array}{c}\text { Total } \\
\text { (100 max) }\end{array}$} \\
\hline & FtF & Online & FtF & Online & FtF & Online & FtF & Online & $\mathrm{FtF}$ & Online \\
\hline M & 23.5 & 22.9 & 23.8 & 23.4 & 24.3 & 21.7 & 19.3 & 20 & 91 & 87.9 \\
\hline$S D$ & 2.1 & 2.1 & 1.3 & 1.8 & 1.4 & 4 & 2.9 & 2.6 & 5 & 5.7 \\
\hline
\end{tabular}

While similar in other categories, the means are noticeably different in the Use of Sources. This difference contributes to the online totals being more than 3 points lower. However, the standard deviation in the Use of Sources category is noticeably greater for the online scores, suggesting that outliers lowered the online means in the Use of Sources and Total columns. Indeed, while among the Use of Sources scores in the face-to-face cohort, there was one 20, with others being 23 and up, in the online cohort, there was one score of 10, one 17, and one 19. However, another indicator regarding source use in the online participants' final research papers was of concern: Eight of them received an instructor's written comment in the Use of Sources category while in the face-to-face class, there was only one such comment. These written comments indicated the need for using more sources throughout the paper, reducing the number and size of quotations by paraphrasing and summarizing the original language, signaling the use of original language with quotation marks, and citing sources.

\section{Analysis of Student-Student Interaction}

While face-to-face students have the opportunity to socialize in regular physical meetings, as well as in online class discussions, online students build social relationships primarily, and often exclusively, via online discussions. It was important for us to get a sense of the quality of our study participants' interaction because the social relationships resulting from such interactions affect their learning outcomes and satisfaction with the course. This section compares the face-to-face and online cohorts in terms of the word counts and rhetorical moves establishing social relationships in discussion-board replies and peer critiques. 
Word counts. Table 3 compares the word counts in two sets of replies to discussion-board posts (29 in each cohort) and two sets of peer critiques (28 in each cohort).

Table 3

Total Word Counts in Discussion Replies and Peer Critiques ( $n=57$ per Cohort)

\begin{tabular}{lcc}
\hline & Face-to-Face & Online \\
\hline Total Word Count & 11,583 & 14,281 \\
Median & 211 & 254 \\
$M$ & 203.2 & 250.5 \\
$S D$ & 81.1 & 164.3 \\
\hline
\end{tabular}

This comparison reveals that in the online cohort, the total word count, the median, and the mean are much greater than in the face-to-face cohort. However, the standard deviation is more than twice as high in the 57 discussion replies and peer critiques of the online participants, signaling outliers. Indeed, one online participant wrote up to 4 times more than specified by the assignments, strongly influencing the cohort's average word count. Another factor that caused a tangible difference in the two total word counts was that while the assignment for peer critiques in the face-to-face class required 225 words per critique, this assignment in the online class required 275 words. To adjust for this difference, we compared the percentages of the word counts in peer critiques only, calculated with the following formulas: (word count $\times 100) / 225$; and (word count $\times 100) / 275$. The results are summarized in Table 4 .

Table 4

Percentages of Word Counts in Peer Critiques ( $n=28$ per Cohort)

\begin{tabular}{lcc}
\hline & Face-to-Face & Online \\
\hline Median & 111.6 & 109 \\
$M$ & 113 & 129.5 \\
$S D$ & 24 & 61.2 \\
\hline
\end{tabular}

With this adjustment for the difference in the required word counts, the medians and the means indicate that in both cohorts, participation in the peer critiques was comparable, while a significant difference between the standard deviations can be explained by one participant whose posts tended to exceed the required word count by as much as 4 times.

Discourse analysis of social moves. Table 5 presents the frequencies of rhetorical moves that established social relationships in discussion replies and peer critiques in the face-to-face and online cohorts. These moves included Encouragement, Deferring, Salutation, and Signing Off (Hewings et al., 2009), as well Criticism, Direct Address (addressing the classmate with 
you and your), and Indirect Address (referring to the classmate in the third person). The Direct and Indirect Address moves were not mutually exclusive: some posts had both.

Table 5

Frequencies of Social Moves in Discussion Replies and Peer Critiques ( $n=57$ per Cohort)

\begin{tabular}{lcc}
\hline & Face-to-Face & Online \\
\hline Salutation & 5 & 48 \\
Signing Off & 11 & 30 \\
Direct Address & 21 & 47 \\
Indirect Address & 42 & 10 \\
Deferring & 6 & 17 \\
Encouragement & 54 & 51 \\
Criticism & 58 & 55 \\
\hline
\end{tabular}

The online participants' discussion replies and peer critiques by far exceeded their face-to-face counterparts in terms of Salutation, Signing Off, and Direct Address. On the contrary, the face-to-face cohort used Indirect Address considerably more often. Deferring was more frequent in the online cohort. When students defer to the class to support their statements, such deferral is an important marker of social relationships in the class. However, both the online and face-to-face participants in our study deferred to the instructor, the assignment, or the textbook, and never to classmates or the class as a whole. The Encouragement (including praise) and Criticism were used with similar frequency in both cohorts; such use was probably in compliance with the assignment's requirement to point the strengths and weaknesses of the classmate's discussion response or draft.

Corpus analysis for the frequencies of pronouns. Table 6 reports the results of a corpus analysis of the discussion replies and peer critiques in the face-to-face and online cohorts counting the uses of the pronouns youlyour; we/us/our; and he/him/his/she/her.

Table 6

Frequencies of Pronouns you/your, we/us/our; and he/him/his/she/her in Discussion Replies and Peer Critiques ( $n=57$ per Cohort)

\begin{tabular}{lcc}
\hline & Face-to-Face & Online \\
\hline you/your & 212 & 502 \\
he/him/his/she/her & 226 & 38 \\
we/us/our & 31 & 50 \\
\hline
\end{tabular}

The uses of second-person pronouns (you/your) were more than twice as frequent in the online cohort, while third-person pronouns (he/him/his/she/her) 
predominated in the face-to-face cohort. The pronouns we/us/our were used slightly more often by the online participants than by the face-to-face ones.

\section{Analysis of Students' Evaluative Feedback on the Course They Took}

It was also important for us to assess students' perception of each course to determine whether there were any significant differences or gaps for those who enrolled in the fully online course. All students participated in the same university-administered course evaluation process, though online students had to answer four additional questions about the technology-related aspects of the online course. It is important to note that because evaluations were anonymous, we were not able to separate the study participants from the general population of the students in the face-to-face course; therefore, we are summarizing from 33 evaluations for the face-to-face sections and 15 from the online section.

On the Likert-type scale, average scores were nearly identical for both groups across a number of criteria including level of engagement, amount learned, quality of feedback, and the knowledgeability and overall quality of the instructor. Face-to-face students provided a higher average rating for general coverage of course learning objectives, however. There were slight differences in the extent to which students perceived gains on more targeted learning objectives, with online students reporting somewhat higher achievement in terms of understanding writing tasks; improving ability to read and apply information from sources; understanding academic integrity; and managing feedback. Face-to-face students' average ratings were higher for increasing library research ability and improving academic language use. In terms of the additional categories that were added to evaluations for the online version of the class, the average score was $4.6 / 5$ for the organization of materials in the learning management system and for the extent to which multimedia enhanced learning. Students strongly agreed that their technology skills improved (4.8/5) but rated the quality of technology support somewhat lower (4.4/5).

In the university-administered course evaluations, students were also able to provide responses for two open-ended prompts: strengths of the course and suggestions on how to improve the course. For the face-to-face version, there were 10 comments on the strengths of the course, and most were fairly generic indications of improvement in writing skills, satisfaction with class activities, or praise for the instructor. There were nine comments about suggestions to improve, but half of these indicated that nothing needed to be improved; one suggestion noted the content was not applicable to the student's major, and two expressed a desire for more oral presentations.

Students in the online version of the course made a few similar comments on strengths and suggestions for improvement; however, the comments they offered were much more specific and often geared toward the online elements 
of the class. For example, several students commented on the convenience and flexibility of the online format and the timely feedback they received. Despite not sharing a physical space with their classmates or instructor, several students remarked on the level of engagement with both, though one student commented about feeling "sad" that students and instructor did not have a chance to get to know one another in person. There was one comment that the course helped with adaptation to the teaching mode at the university. In general, multimedia elements were seen as beneficial to learning; however, five out of the eight suggestions for improvement targeted interactive elements of the class, including the need for more video lectures, lack of time to watch existing video lectures, and the desire for a greater focus on oral presentations.

For the online version of the class, the instructor also administered a separate survey with an additional set of 15 questions that were drawn from Fink (2003); however, only five students completed this survey so results should be interpreted cautiously. Students highly rated the quality of interaction with both peers and the instructor, as well as the instructor's responsiveness. When asked what most helped them achieve their learning goals, respondents tended to mention academic writing; yet, at the same time, they acknowledged that they needed to continue building their skills in vocabulary and writing. Interestingly, when asked which elements of the class they found most engaging, two students mentioned watching their classmates' video presentations; two offered writing- or research-related comments; and one felt most engaged as a result of viewing the instructor's feedback online. Technological issues came up in several comments, but there were no obvious trends in students' survey responses. Overall, it was clear that the students had a positive view of the learning experience.

\section{Discussion and Conclusions}

This comparative case study explored the experiences and outcomes for two cohorts of international graduate students who were enrolled in a required EAP writing class; one group $(n=15)$ took a face-to-face version of the course, and one $(n=15)$ completed the course online. Applying a comparative case study methodology, with an action research orientation, enabled us to generate a more robust set of findings than conducting a study of the online course only. As indicated in the Results section above, our key finding was a high level of comparability in participants' overall experience; however, more nuanced differences emerged when we examined their final research papers, online interactions, and course evaluations.

Our data analysis revealed that participants' final EAP course grades and GPA in the first year of study in their graduate programs were highly comparable, which allows us to conclude that students were not disadvantaged as a result of enrolling in an online version of the class the summer before matric- 
ulating in their graduate programs. Obviously, this was a key consideration for us at the program level, especially as a central goal for EAP is preparing students with the academic literacy skills that will support their success in their studies (De Chazal, 2014; Hyland \& Hamp-Lyons, 2002). Other research has found outcomes in online learning to be comparable with those in faceto-face classes (Allen \& J. Seaman, 2016; Grgurovic et al., 2013; Harker \& Koutsantoni, 2005), though our study was unique in that it comparatively assessed L2 writing learning in a fully online required course, rather than examining the outcomes of supplemental or optional online instruction. Our findings also map with the existing literature's characterization of the learning benefits of online courses (Garrison, 2017; Hsieh \& Liou, 2008; Warnock, 2009). In addition, university-administered course evaluations and surveys of online students' experience in the class indicated that students valued the opportunity to take this course in a more flexible format and from their home country prior to arrival in the host country.

Some of the challenges outlined in previous research were not found in our study. For example, unlike the findings of Harker and Koutsantoni (2005), there was no attrition, students remained engaged, and all students successfully completed the course. We also had little sense that students lacked motivation due to poor communication from the instructor, as Karkar-Esperat (2018) found, or that students felt isolated as a result of the online format (Starr-Glass, 2014). In fact, we found that a number of students commented on interaction with their peers and instructor as a valuable element of the class. We attribute this to the extent to which the instructor thoughtfully embedded interactive elements into the classes and made certain that students had multiple and diverse opportunities to interact via online discussion and VoiceThread postings, and that they received timely and personalized feedback on their written work and oral presentations. Such careful course design, in turn, was based on comprehensive support provided by the university, which incentivized the instructor with a stipend and provided the services of instructional designers who helped the instructor with the pedagogical and technical aspects of the online course. Lack of such support has been found to be a major obstacle for ESL instructors' adoption of e-learning in Canada (Lawrence et al., 2014; Shebansky, 2018). Our experience confirms Shebansky's (2018) assertion that "providing a job-embedded, ongoing, mentorship model of professional development . . . with relevant technical training and support, recognizing time commitment through financial compensation, and resolving technology problems promptly is a good start and will encourage instructor buy-in" (p. 71).

Less clear is the extent to which our online course "socialized" new graduate students into their new academic discourse community, which Casanave and $\mathrm{Li}(2008)$ and Curry (2016) argue is key in graduate contexts. We assume that regular interaction with the instructor and peers helped. Also, to promote disciplinary and genre socialization, the online course included video- 
recorded interviews with faculty from students' respective disciplines and assignments that required students to research authentic genres and issues related to their field of study. However, despite the fact that the online students completed the same assignments and mastered the same course content as the face-to-face students, which helped us assess comparability between the two formats, further research is needed to understand how the lack of access to the physical space of the university may have shaped their experience.

Another potential gap in the initial online offering of the course was revealed in our comparison of the study participants' performance on the course's main assignment, a source-based argumentative research paper on an issue in their field of study. Our analysis indicated that while both cohorts did equally well in other areas, some online participants had problems using sources, including failing to establish boundaries around original source material, quoting excessively instead of summarizing and paraphrasing, and neglecting to cite sources. This difference could be explained by the fact that in face-to-face settings, students may learn source integration from numerous informal consultations with the instructor or their peers, in or out of class. These situational and contact-driven learning opportunities are assumed to be particularly important for "new" students who are acclimating to the principles and practices of source use in a North American higher educational context. Such informal contacts are challenging to replicate in a fully online environment.

The issue of source use also warrants additional exploration of an aspect of learning that is relatively difficult to integrate into an online format: library research. The students taking the face-to-face EAP class not only had regular physical access to the library and librarians, but they also attended a dedicated workshop where they learned how to conduct academic research and evaluate sources. The students in the online course had online access to the university library and "virtual" support and instructional guidance, but despite reporting that they gained skills in these areas on end-of-course evaluations, they still struggled with library research and source integration in their research papers. These skills should obviously receive more focused attention in our future online classes, including more instruction and applied practice.

Despite these challenges, which may in part be attributed to students' lack of presence on campus, we identified promising results in regard to interactivity. Asynchronous online student-student interaction is a defining feature of online education, but it is also highly beneficial for face-to-face students. By regularly posting to discussion boards, students practice writing and participate in class discussions more deeply and consistently than they do in oral conversations in the classroom. Such interactions are also an important space for developing social relationships in a class, especially in an asynchronous online class. To be successful, online interactions must be guided with clear instructions and requirements. Otherwise, they are 
in danger of becoming chaotic and meaningless (Warnock, 2008, p. 71), or they may serve as a platform for "serial monologues" in which participants freely share their opinions and experiences but engage classmates' posts only superficially if at all (Pawan et al., 2003). Yim's (2011) research in a Canadian context also confirms the instructor's role in promoting social relatedness and a rich intellectual exchange in asynchronous online discussions.

Our analysis of the study participants' discussion replies and peer critiques showed that, as required by the assignment, they engaged classmates' posts effectively by providing abundant encouragement and constructive criticism. However, our study yielded mixed results in regard to rhetorical moves, which, according to previous research, are important for creating social relationships and nurturing a sense of community (Beuchot \& Bullen, 2005; Hewings et al., 2009; Yim, 2011). No instruction had been provided to the students about rhetorical moves, and our analysis revealed that while commenting on their classmates' discussion responses and drafts, face-to-face participants rarely offered a salutation or personalized sign-off to their classmates, and they were more likely to refer to their classmates in the third person. In other words, in their online interactions, most face-toface participants addressed the instructor, not their classmates. We noticed the opposite dynamic in the online cohort, in which the absolute majority of replies and peer critiques included salutation, sign-off, and other direct forms of address. A corpus analysis confirmed a much more frequent occurrence of the pronouns you/your in the online cohort, and of he/him/his/she/her in the face-to-face one. These findings suggest that in discussion-board posts, social relationships formed more actively in the online version of the EAP class, perhaps in response to the lack of classroom-based interaction. Despite these encouraging findings, the presence of social relationships conducive to learning in our online class remained uncertain. To cultivate the formation of such relationships in online interactions, students must be taught explicitly to use rhetorical moves and pronouns and to defer to the class and classmates as a repository of shared knowledge for supporting claims and criticisms.

The findings of this comparative case study add to the research base on online learning and are particularly valuable because they explore a fully online academic writing course for L2 international graduate students. This aspect of our research complements recent scholarly work on supporting graduate student writers (Simpson et al., 2016). This study, however, has limitations. First, the study participants fit a relatively narrow demographic profile: Chinese graduate students from predominantly science, technology, engineering, and mathematics (STEM)-related fields. Although this reflects the overall enrollment pattern at the university and more broadly in Canadian and U.S. higher education, we acknowledge that our findings may have differed with a more diverse set of L2 participants, or a mixture of L1 and L2 students. We encourage future research that focuses on different student populations and/or on online courses that target specific disciplines or profes- 
sional fields. Second, the fact that this course was both required and offered for academic credit may have also motivated students to engage more fully with the learning experience; furthermore, graduate students tend to be more mature and invested in achieving their educational goals.

In addition, it should be acknowledged that though the instructor, course content, learning objectives, and the workload of $112.5 \mathrm{hr}$ per semester were the same in both the spring (face-to-face) and summer (online) offerings of the course, the length of the semester was 14 weeks in spring and only 6 weeks in summer. This meant that the summer session was considerably more intense for both the students and the instructor. It could be argued that the direct and sustained contact the students had in the summer online course allowed for a deeper engagement, as opposed to the spring semester when students taking the face-to-face EAP class were also enrolled in as many as three courses within their graduate programs. However, as Keefe and Shi (2017) noted in their study focusing on an 8-week EAP course offered in the summer at a Canadian university, "the process for international students to fully engage with a new university is slow and evolving" (p. 20). Thus, even though our findings indicate that our face-to-face and online participants' GPAs in their first year of study were comparable, more research is needed into how the intensive nature of the EAP online course offered in the summer affects students' experience.

Despite these limitations, the idea that EAP programs like ours can leverage summer online as an opportunity to develop students' academic literacy skills before arriving on campus and immersing themselves in their graduate programs holds considerable promise. On a program level, the findings of this study lay the groundwork for further refinement of the existing online course and development of future courses, which may serve as a model that other programs and institutions can benefit from. Based on the successful pilot of the lower level academic writing course in summer 2018, we developed and piloted an online section of the upper level academic writing course in summer 2019 and offered two sections of the lower level online course. Moving forward, we expect demand to be high for both courses, which will necessitate a thoughtful approach to replicability and the preparation of new instructors to teach the online sections. Continued offerings of high-quality online courses will enable the EAP program to ensure a more streamlined approach to the delivery of course content, free up instructor time to engage with students online and offer feedback, increase revenue flow due to the more favourable summer budget model, and offset its heavy demand for sections during the fall semester.

On a broader level, we recommend more research into the way fully online courses can better reflect aspects of socialization to a new discourse community and replicate access to elements of learning that are more organic in classroom settings, such as library research and directed guidance on source integration and citation. Although the instructor's virtual presence 
in the online course was demonstrated by direct engagement with students via instruction and feedback, the online students had limited access to writing support at the university, including librarians and writing centre tutors. Further work needs to be done on incorporating these support elements into online classes and possibly offering students ways to interact virtually with faculty, staff, or fellow students on the university's campus. Similarly, exposing students to the disciplinary expectations and community of their home department would also promote their socialization into their new academic discourse community.

Our findings also invite further research on fully online asynchronous course offerings, with more targeted research into the extent to which social relationships conducive to learning can be created and maintained in such settings. The application of discourse and corpus-based analysis holds great promise for research into understanding the quality of students' interactions in online learning. It would also be helpful to conduct research into how social interaction is promoted through multimodal technologies such as VoiceThread.

In conclusion, the development of the online version of this EAP academic writing course for international graduate students was driven by both necessity and opportunity. To respond to recent increases in international student enrollment and institutional initiatives to internationalize, universities and programs need to consider innovative ways to offer instruction that fits their students' needs. A key opportunity has arisen with the increased focus on online learning and universities' willingness to invest in developing online courses. This comparative case study reinforces the value of online course offerings, especially in contexts where L2 international students are required to complete EAP coursework as part of their admission to the university.

\section{Acknowledgement}

We would like to express our gratitude to Maddy Kadish and Samantha Nagy, instructional designers at the George Washington University, for their substantial contribution to the design of the online course described in this article. We would also like to thank Amanda Rollins and Dasha Kanevsky, department administrator and student assistant at the English for Academic Purposes program at the George Washington University; they helped us collect and organize data reported here.

\section{The Authors}

Dmitri Stanchevici, PhD, is a teaching assistant professor of English for Academic Purposes (EAP) at the George Washington University, Washington, D.C. His research interests include technical and scientific communication, writing studies, and e-learning. His scholarly publications include articles in Health Communication and Journal of Technical Writing and Communication and his book Stalinist Genetics: The Constitutional Rhetoric of T. D. Lysenko.

Megan M. Siczek, EdD, serves as director and assistant professor of the EAP program at the George Washington University, Washington, D.C. Her research interests include second language writing and the internationalization of higher education. She has published journal articles about global education initiatives and interpretations, chapters in several edited collec- 
tions in the field of second language writing, and is the author of the book International Students in First-Year Writing: A Journey Through Socio-Academic Space.

\section{References}

Allen, I. E., \& Seaman, J. (2016). Online report card: Tracking online education in the United States. Digital Learning Compass: Distance Education Enrollment Report 2017. Babson Survey Research Group. Retrieved from https://onlinelearningsurvey.com/reports/onlinereportcard.pdf

Anthony, L. (2019). AntConc (Version 3.5.8) [Computer Software]. Tokyo, Japan: Waseda University. Retrieved from http://www.laurenceanthony.net/software

Beuchot, A., \& Bullen, M. (2005). Interaction and interpersonality in online discussion forums. Distance Education, 26(1), 67-87. https://doi.org/10.1080/01587910500081285

Burgstahler, S. E., \& Cory, R. C. (2008). Universal design in higher education: From principles to practice. Cambridge, MA: Harvard Education Press.

Casanave, C. P., \& Li, X. (2008). Learning the literacy practices of graduate school: Insiders' reflections on academic enculturation. Ann Arbor: University of Michigan Press.

Colpaert, J. (2006). Pedagogy-driven design for online language teaching and learning. CALICO Journal, 23(3), 477-497. Retrieved from https://www.jstor.org/stable/24156348

Curry, M. J. (2016). More than language: Graduate student writing as "disciplinary becoming." In S. Simpson, N. Caplan, M. Cox, \& T. Phillips (Eds.), Supporting graduate student writers: Research, curriculum and program design (pp. 78-96). Ann Arbor: University of Michigan Press.

De Chazal, E. (2014). English for academic purposes. Oxford: Oxford University Press.

Donovan, T., Bates, T., Seaman, J., Mayer, D., Martel, E., Paul, R., Desbiens, B., Forssman, V., \& Poulin, R. (2019). Tracking online and distance education in Canadian universities and college: 2018. Canadian Digital Learning Research Association. Retrieved from https://onlinelearningsurveycanada.ca/publications-2018/

Fink, L. D. (2003). Creating significant learning experiences: An integrated approach to designing college courses. San Francisco, CA: Wiley.

Garrison, D. R. (2017). E-learning in the 21st century: A community of inquiry framework for research and practice. Third edition. New York: Routledge.

Government of Canada. (2019). Temporary residents: Study permit holders-Monthly IRCC update. Retrieved from https://open.canada.ca/data/en/dataset/90115b00-f9b8-49e8-afa3-b4cff8facaee

Grgurovic, M., Chapelle, C. A., \& Shelley, M. C. (2013). A meta-analysis of effectiveness studies on computer technology-supported language learning. ReCALL, 25(2), 165-198. https://doi. org/10.1017/S0958344013000013

Harker, M., \& Koutsantoni, D. (2005). Can it be as effective? Distance versus blended learning in a web-based EAP programme. ReCALL, 17(2), 197-216. https://doi.org/10.1017/ S095834400500042X

Hewings, A., Coffin, C., \& North, S. (2009). E-conferencing: Corpus and discourse insights. In M. Charles, D. Pecorari, \& S. Hunston (Eds.), Academic writing: At the interface of corpus and discourse (pp. 129-151). London: Continuum.

Hsieh, W.-M., \& Liou, H.-C. (2008). A case study of corpus-informed online academic writing for EFL graduate students. CALICO Journal, 26(1), 28-47. Retrieved from https://www.jstor. org/stable/calicojournal.26.1.28?seq=1\#page_scan_tab_contents

Hyland, K., \& Hamp-Lyons, L. (2002). EAP: Issues and directions. Journal of English for Academic Purposes, 1(1), 1-12.

Institute of International Education. (2019). Open doors data. Retrieved from https://www.iie.org/ Research-and-Insights/Open-Doors/Data/International-Students/Enrollment

Jarvis, H. (2001). Internet usage of English for Academic Purposes courses. ReCALL 13(2), 206212. 
Karkar-Esperat, T. M. (2018). International graduate students' challenges and learning experiences in online classes. Journal of International Students, 4, 1722-1735. Retrieved from https:// ojed.org/index.php/jis/article/view/227

Keefe, K., \& Shi, L. (2017). An EAP program and students' success at a Canadian university. TESL Canada, 34(2), 1-24. https://doi.org/10.18806/tesl.v34i2.1264

Lawrence, G., Haque, E., King, J., \& Rajabi, S. (2014). Exploring the feasibility of e-learning in Ontario ESL programs. Contact, 40(1), 12-18. Retrieved from http://www.teslontario.net/uploads/publications/contact/ContactSpring2014.pdf

Liu, X., Liu, S., Lee, S.-H., \& Magjuka, R. J. (2010). Cultural differences in online learning: International student perceptions. Educational Technology \& Society, 13(3), 177-188. Retrieved from https://www.jstor.org/stable/jeductechsoci.13.3.177

McNiff, J. (2013). Action research: Principles and practice. London: Routledge.

Pawan, F., Paulus, T. M., Yalcin, S., \& Chang, C.-F. (2003). Online learning: Patterns of engagement and interaction among in-service teachers. Language Learning \& Technology, 7(3), 119-140. Retrieved from https://www.learntechlib.org/p/97689/

Shebansky, W. J. (2018). Blended learning adoption in an ESL context: Obstacles and guidelines. TESL Canada, 35(1), 52-77. https://doi.org/10.18806/tesl.v35i1.1284

Seaman, J. E., Allen, I. E., \& Seaman, J. (2018). Grade increase: Tracking distance education in the United States. Babson Survey Research Group. Retrieved from https://onlinelearningsurvey. com/reports/gradeincrease.pdf

Séror, J. (2012). Show me! Enhanced feedback through screencasting technology. TESL Canada Journal, 30(1), 104-104. https://doi.org/10.18806/tesl.v30i1.1128

Simpson, S., Caplan, N. A., Cox, M., \& Philips, T. (Eds.). (2016). Supporting graduate student writers: Research, curriculum, and program design. Ann Arbor: University of Michigan Press.

Slavkov, N. (2015). Sociocultural theory, the L2 writing process, and Google Drive: Strange bedfellows? TESL Canada Journal, 32(2), 80-94. https://doi.org/10.18806/tesl.v32i2.1209

Stapleton, P. (2003). Assessing the quality and bias of web-based sources: Implications for academic writing. Journal of English for Academic Purposes, 2, 229-245. https://doi.org/10.1016/ S1475-1585(03)00026-2

Starr-Glass, D. (2014). Internalizing cross-cultural sensitivity: Reflective journals of migrant students. Journal of International Education in Business, 7(1), 31-46. https://doi.org/10.1108/ JIEB-07-2013-0028

Statistics Canada. (2018). Canadian postsecondary enrolments and graduates, 2016/2017. Retrieved from https://www150.statcan.gc.ca/n1/daily-quotidien/181128/dq181128c-eng.htm

Vorobel, O., \& Kim, D. (2012). Language teaching at a distance: An overview of research. CALICO Journal, 29(3), 548-562. Retrieved from https://www.jstor.org/stable/calicojournal.29.3.548

Warnock, S. (2009). Teaching writing online: How \& why. Urbana, IL: National Council of Teachers of English.

Xing, M., Wang, J., \& Spencer, K. (2008). Raising students' awareness of cross-cultural contrastive rhetoric in English writing via an e-learning course. Language Learning $\mathcal{E}$ Technology, 12(2), 71-93. Retrieved from http://ltt.msu.edu/vol12num2/xingetal/

Yim, Y. K. K. (2011). Second language students' discourse socialization in academic online communities. Canadian Modern Language Review, 67(1), 1-27. https://doi.org/10.3138/cmlr.67.1.001

Yin, R. K. (2017). Case study research and applications: Design and methods. Thousand Oaks, CA: Sage.

Zhang, X. (2018). Innovating selection and use of online writing resources for EFL students: A systemic functional linguistic perspective. iJET, 13(9), 136-147. https://doi.org/10.3991/ijet. v13i09.7910 